\title{
Changes and Challenges in the Teaching of Grammar in the Age of Disruption
}

\author{
Luisito M. Nanquil \\ Bulacan State University, Philippines \\ Corresponding Author: Luisito M. Nanquil, E-mail: luisito.nanquil@bulsu.edu.ph
}

\author{
ARTICLE INFO \\ Received: August 08, 2021 \\ Accepted: September 05, 2021 \\ Volume: 1 \\ Issue: 1 \\ DOI: $10.32996 / j l d s .2021 .1 .1 .1$
}

\section{KEYWORDS}

Grammar, challenges, changes, strategies, pedagogy

\section{ABSTRACT}

The teaching of grammar during classroom meetings is entirely different from the grammar instruction in the new normal. The learning and teaching atmosphere has been more challenging in the contemporary time because people want to be safe and secure as they do transactions. The widespread threats of the pandemic forced humanity to observe mandatory policies and protocols in work, school, and home. Development of language skills is a long time thrust by which ESL teachers carry among their schools. In the Philippine setting, both private and public school teachers share common problems in a different context and situation. The importance of grammar skills can be reflected on the various tasks and activities performed by people in the worksite, academe, and industry. As such, language teachers confront the issues and challenges in the actual ESL classroom where students are expected to learn and master grammar skills among others. Not all students have a good language facility as shown by poor performance in the English language assessments. Some students dislike inclusion of grammar lessons in the curriculum for fear of being unable to participate in the class and produce outputs. This paper aims to identify and describe the challenges (in the time of pandemic) experienced by language teachers on the teaching of grammar in the local Philippine context. Before the study culminated, the researcher has decided to get the views of experts and experienced ESL teachers about this problem and/or issue. It is a fact that has been observed and proved by many teachers not just ESL area but other majors that having grammar competence can help both students and professionals to achieve their goals and perform communicative tasks in the workplace. Results of the study provided insights and tips on how language teachers can make grammar teaching effective and relevant despite changes in setting and environment.

Published by Al-Kindi Center for Research and Development, London, United Kingdom

Copyright (c) the author(s). This open access article is distributed under a Creative Commons Attribution (CC-BY) 4.0 license (https://creativecommons.org/licenses/by-nc-nd/4.0/)

\section{Introduction}

The pandemic lockdown around the world has affected the lives of people from all walks of life. Many schools and centers have no choice but to close and cease operations due to rapid decline of enrollees, health issues and other related concerns (all brought about by health crisis). In the present condition, even the learning situation is vastly affected due to lockdown and health protocols disallowing students and employees to report in offices and schools. Education agencies and government decided to continue the learning process because they believe that despite disruption of pandemic, learning should proceed using different modalities. However, learners in some areas of the world including the Philippines, are having hard time meeting the requirements in school because of many issues and among them is connectivity. In the period of uncertainty, language teachers are challenged on how they can still develop the grammar competence of their students. If during the onsite classes or traditional classroom sessions, evident problems in communication and grammar were seen, how much more in the online space or virtual environment. Students of different grade levels are having laborious moments mastering grammar lessons which has become even more challenging due to online classes in the absence of stable and reliable connectivity.

With the views of language teachers and experience of the researcher, this paper has attempted to explain reasons why learners are struggling to develop grammar competence, in the same manner, results of the study formed feasible and possible insights and practices to address such problems in the online class of the new normal. In the form of recommendations, this study is 
useful to many workers and professionals in the field of language teaching. It will open opportunity for assessment, reflection, further research, and peer coaching. Moreover, the results and findings of the study are invaluable to development and preparation of materials and resources that are badly required in classroom settings. It is entirely different now because most lessons are delivered on the virtual space which requires connectivity among other tools and elements.

The importance of English is tangible and observable as described by British Study Centre on their official website. Proponents and experts often describe English as the language of opportunities and so, the language of the world. Through this language, many students, teachers, and professionals are able to communicate with others not just on the country where they live but also in overseas where they can experience and feel cultural diversity. Learning English will pave way to rare opportunity of knowing and interacting with another culture and civilization; hence, it will increase your understanding and empathy. As mentioned on the website, English is the language of trade, commerce, business, science, and technology. This means that wherever people may go, they are filled with abundant opportunities that will help them land stable work. There are countless ways and reasons why choosing English as an additional language can give you boundless opportunities that you can imagine and feel.

Here are 10 insightful reasons why you should consider English as your course.

1. English is being used by many countries and peoples around the world. A gigantic number of users will mean you will not be alone and you will be understood.

2. English is the language of trade, commerce, and industry. Through this language you can get the chance to follow directions and procedures when you are applying for a job. This language also brings you to multicultural and multilingual environment.

3. Many countries use English as their official language, which means you can meet a lot of people.

4. English is being used by millions of peoples around the globe.

5. English is the language of social media and mass media. Through your comprehension and ability to speak this language you will be updated and informed of trends and changes.

6. English is regarded as the language of the internet which only implies that many of the resources and data you need are translated in English language.

7. Compared to other languages, English is much easier to learn because of simple structure.

8. English can give you feeling of satisfaction especially when you are able to learn it quickly and smoothly.

9. Since English is widely spoken around the world, students and teachers can get the chance to study among the best universities.

10. Through English, you can study other cultures and traditions because you will meet other people in the world.

\subsection{Objective of the Study}

The primary objective of this paper is to examine and describe the challenges and changes in the teaching of grammar as experienced by select language teachers in the Philippines.

\section{Theoretical background}

The researcher reviewed related literatures and studies that are invaluable for the development of the study. The said materials helped the study achieve clear directions regarding the main issue being investigated herein.

This study was developed through analysis and connection of comprehensive conceptualization of grammar offered by experts and theorists. The study of grammar is within the framework of linguistics where higher order concepts are being studied such as structure, meaning, and function. According to some findings, the interrelated dimensions of language are very essential to language specialists and linguists because they provide the foundations needed to achieve linguistics repertoire. Nunan (2009), Halliday (1985), and Freeman (1995) were among the leading figures who provided deep and detailed facts on how the field linguistics was explored and examined. Their contributions to the current study of grammar have brought higher ideas and studies which have benefitted many linguistics and language teachers of the contemporary period. Their findings have practically educated and oriented language teachers how grammar and its structure can be used to convey messages and information.

According to Richards, Platt, and Weber (1985), grammar is a set of rules that show the accurate or correct order of words in a sentence level. The Longman Dictionary of Linguistics as cited by Richards et. al says grammar is the description of the language with units such as words and phrases combined to form meaningful sentences. 


\subsection{Background to the teaching of grammar}

The position of grammar in the language classroom has had a rather changeable history. Thirty years ago, language teaching and grammar teaching were identical in most language classrooms. The foremost aim of teaching was to ensure that learners acquired the grammar, pronunciation, and vocabulary (Nunan, 2003).

Understanding language and grammar helps pupils and students explore what is happening in the English classroom. Our ability to communicate is sustained by the knowledge we have for the two essential elements. It is no doubt that those who possess language competence go places and achieve success. They are able to adjust and adapt the workplace where they can showcase their talents and skills.

What represents human beings as a key part is their language. It expresses their individuality and belongingness to a group. This idea is true to both young and adult learners. Young people are immersed in language when they interact with others even with the aid of technology. They use language to understand others, to communicate their thoughts, to establish networks, and to cope with transitions in the society where they are living.

In one of the topics of Murcia's book, grammar is widely discussed on how it can be incorporated into writing instruction.

Krashen (1982) stated that some students can write rich but with poor grammar and is influenced by L1 pedagogy and research. He argued that focused instruction is unnecessary but thwarts natural acquisition processes. Silva (1993) realized from his synthesis that first and second language learners have peculiar ways of developing their writing skills as possibly related to the learning atmosphere with the guidance of the teacher and the people surrounding them.

Frodesen and Holten (2003) have stressed that second language classroom teachers deal with various challenges and barriers on teaching of composition because of the changing needs and attitudes of the learners when it comes to grammar, language, and writing lessons and tasks.

Although they clearly offer very different types of instruction, both the calligraphy rich but grammar poor and the grammar rich, but writing poor classes reflect misconceptions about the role of grammar in the teaching of writing. Research shows that there is a big difference on how language forms and structures are being taught to learners and how language forms or structures are taught using the context of a particular lesson and or place. Other experts believe that the bilingual classroom may be a factor on the provision of fascinating or favorable learning experience of the children.

Language students should not just learn and master language because of completion in a particular grade level, but for various purposes that they will do in the future. If students realize that learning a language is more than the thought of passing a particular subject and grade, they will discover how many and how much they can get from it. They should realize its value by active participation among activities, joining organizations, making new circle of friends, asking and receiving information and a lot more. Learners should also come to understand that grammar is an essential component of a language to meet the communicative needs of people and the gleaming functions it will offer. Indeed, the place of grammar in communication and socialization is indispensable as proven by various studies and practical applications.

Regardless of its variation, regional dialects should never be rejected because they have their own rule, form, and meaning. Furthermore, they can be an aid to learning another language as supported by translanguaging studies.

Competence in communication is necessary in all occasions and situations because people, as social beings, always need to express themselves by conveying their thoughts, ideas, and reasons. Through communication, they can inquire and ask questions. They can obtain bits of information and disseminate this information to others in variety of ways. In this matter, we can conclude that discourse plays a big role in the success of every person either students or professionals. The benefits of being language competent are tangible and considerable. In this globalized world, the ability communicate is a must for all peoples especially employees who would like to participate in both local and international affairs. If you have this trait, you would surely achieve a big difference in life because you would be influential and persuasive communicator.

English teaching around the globe has evolved and developed over the years in order to suit varying needs of learners. Among others, attitudes of learners in learning and using the English language have changed considerably. On the first five decades of the $20^{\text {th }}$ century, English teaching included a great deal of prescriptive grammar teaching with an emphasis on repetitive exercises, artificial examples and parsing, when students had to identify all the component parts of a sentence. Pupils were taught rigid rules such as that you cannot begin a sentence with the word 'and' - despite the fact that many writers choose to do so. This work was anchored on a theoretical model of formal standard English rather than on examination of language as it is actually used. 
Davidson and Downson (2003) believes it is essential to remember that regional dialects are not standard English gone wrong, but are just as ancient and have developed in parallel. Regardless of its variation, regional dialects should never be rejected because they have their own rule, form, and meaning. Furthermore, they can be an aid to learning another language as supported by translanguaging studies.

Conventional language pedagogy, with its emphasis on written-grammar-based norms, usually does not expose learners to a good deal of situational ellipsis in example dialogues, nor does it offer opportunities for learners to develop the skill of using ellipsis appropriately (Carter and McCarthy, 2006).

Young learners and adult learners learn in a different pace and phase. The role of prescriptive and standard English is recognized in language and grammar teaching. The language teacher should not only focus on how the structures of the language are examined and described but he should provide exercises and activities that are meaningful to the point of application to various situations will be seen and experienced by the learners. Many scenes and tasks can be mentioned and explained but clearer pictures of these are best described by situations, tasks, and practical lessons. It is also advised by experts that localization of lessons in language and grammar are highlighted or introduced by the teacher. Studies have shown that when learners are able to see on their place and setting the objects and concepts taught, they can easily remember those.

Recent investigations also claim that children and even adults can achieve fluency in language and grammar if they will use the language forms communicatively. That is, they will move and perform in relation to the setting and workplace they are aspiring for their future. From this practice, they can enhance their communicative competence as they carry out different tasks and goals.

\subsection{Teaching Grammar}

Explicit grammar teaching stays as valuable mainstream of many language courses, and institutional context is a major influence on the policies

The following reminders are options for you to consider and incorporate if necessary.

1. Expect grammar errors. You will encounter and discover lapses of your students on their language. Take that aspect as your way of retooling your methods and strategies and building your materials to address such errors.

2. Provide students with opportunities to use their full grammatical capacity. You may provide meaningful and functional tasks for the learners to improve this language skill. From the grammatical forms, they can do role play, writing, social media engagement and so on. Students can choose what language they want to express based on the lesson discussed.

3. Explore explicit grammatical range. These are interactive activities where language is more controlled. The main purpose of the activity is to practice a recently tackled form. Such activities usually have a meaning-focused dimension, but students are informed and guided what language they should use to convey meaning.

4. Correct errors carefully. One's attitude to accuracy and feedback should depend on the objectives of the activity and on what you think your students desire to learn.

5. Make meaningful discussions. You may teach explicitly a new grammatical form. You can check whether learners have perceived and understood the form using "concept" questions, which highlight an aspect of the situation.

6. Use discovery strategies. An option to grammatical delivery is to show examples of a grammatical form in various settings and to motivate them to work out its importance.

7. Give clear and simple explanations. Simplify your explanation but get prepared for the list of questions from your students by conducting research before meeting the class. See to it that your explanation is suitable to the language awareness stage of your students so that they can easily and comfortably understand your words.

8. Capitalize on learner's existing knowledge. Try to assess and identify the rules known by your students and from there, you may establish and develop techniques to further their knowledge. Their metalanguage of any topics or lessons plays a significant role.

9. Balance the conditions for grammar improvement. Different conditions may help learners at different times. Make sure that lessons or series of topics contain a smooth understanding.

10. Keep on providing healthy and informative atmosphere. Encourage students to read and listen to complex structures they are about to learn. Modify tasks and activities to make the texts more accessible and feasible to your students.

\section{Materials and Methods}

Aiming that this proposed study would produce intervening program in the future, the researcher decided to include appropriate methodology and design. This paper used phenomenology as a qualitative approach of analyzing and describing observations and perspectives to form textual data. There were 10 participants who were a part of this study, and purposive sampling was employed in the rigorous selection process. Among the methods of data collection were interview, online 
observation, and reflection journal. Finally, content analysis was used as method of analysis. The participants were ensured that the data taken from them would be treated with confidentiality and privacy. After obtaining the data, the researcher confirmed with the participants the key concepts and ideas which emerged from the responses.

This research employed qualitative design and methodology. Specific methods of inquiry and tools were used such as interview, online observation, and reflection journal so that real and authentic picture of the phenomenon was captured. A possible endpoint and product of this proposed study is a teaching guide that can be used by public and private school teachers in the Philippines and beyond.

Phenomenology was the approach used in order to check the insights, views, and observations of language teachers as participants of the study.

\section{Results and Discussion}

A thorough examination of the responses of participants revealed that the common challenges they have encountered in the teaching of grammar are: (1) learners are having overgeneralization of the rules thinking that one rule is applicable to all just like in subject-verb agreement; (2) redundancy occurs very frequently; (3) phrasal verbs are unknown to learners; (4) fused sentences; and (5) verb tenses.

Participants, who are experienced language teachers in the Philippines shared that teaching grammar in the new normal and during the time of pandemic has never been as challenging as it is today due to changes and transitions of events and circumstances. A number of students find it hard to connect with their teachers and obtain access to online materials due to unavailability of resources and connectivity.

Many of the language teachers claimed that causes of the grammar problems are lack of materials at home, lack of practice, and limited opportunities to develop grammar competence. Some parents and families believe that before they purchase the materials in English, they would rather meet basic needs first such as food, water, and shelter.

There is also a challenge on how language teachers will be upgraded and improved when it comes to pedagogies, practices, and assessments. Teachers should also try their best to inculcate among their students the value and importance of learning grammar in their life by showing them the context and real life opportunities that they can possibly achieve as tangible benefits.

If only students are aware of the function of grammar as guided by language teachers, they will surely strive harder and work well to become proficient in this skill. Teachers are the at the forefront of nourishing and preparing students and young learners to be confident and accurate in using grammar skills wherever they are and whatever circumstances they are engaged into.

\section{Conclusion and Recommandations}

Previous studies and literatures discussed how language teachers deal with grammar errors and problems of ESL and EFL students. Traditional and modern approaches were being used then based on their studies. In the current situation, still many learners are having laborious time to master the English language and grammar due to many factors such as poverty, lack of materials, and poor reading comprehension among others. It is a big challenge for language teachers to recalibrate and upgrade themselves in terms of content, mastery, and strategy for them to sustain and maintain effective classroom environment. Although the phenomenon global English has been emerging for a number of years, professionals and students still have to observe prescribed grammar rules in the workplace and academe. As problems in grammar continue to disrupt language skills, instructional strategies and approaches will be effective instrument to assist learners to develop competence and confidence.

Primary consideration in the practices and strategies of the teacher is the characteristics of the learners because everyone in the classroom is unique and diverse. This thought requires the language teacher to be sensitive to variables and factors that may promote or hamper learning in the class, among these are needs, experiences, mental capacity, motivation, attitude, and beliefs. Not to forget another crucial factor is socio-economic status because in some schools, classrooms are not equipped with adequate facilities and materials. Hence, creativity and reflection are shield and guide to teachers in their quest for excellence and quality. From the thoughts reflected in this study, it can be justified that film viewing is effective in increasing the vocabulary of the learners at the same time, it further enhances the language proficiency and awareness of the learners. This is more evident if the language teacher himself will guide and direct the learners on what and how to do the pedagogical tasks.

Results of the investigation clearly shows how essential it is for language teachers to be oriented and updated on the trends, issues, and perspectives on language and grammar teaching since problems on this area have been perennial in many schools. The challenges encountered by language teachers will remind them of the possible actionable plans and strategies they can apply to address existing problems and challenges gradually. 
Furthermore, findings of the study revealed how challenging it is to teach grammar to ESL and online classes due to financial constraints and connectivity issues on the part of the learners. As such, various and flexible modalities must be applied by language teachers in order to meet and address the dominant needs and problems on the virtual instruction as caused by the global health crisis. Through determination, patience, and flexibility of the teachers learning grammar will be both exciting and fruitful to learners despite the threat of disruption and uncertainty.

\section{References}

[1] Carter, R., and McCarthy, M. (2006). Cambridge grammar of English: a comprehensive guide: spoken and written English grammar and usage. Cambridge University Press.

[2] Celce-Murcia, M., Brinton, D.M., and Snow, A.S. (2014). Teaching English as a second or foreign language (Fourth Edition). United States: HEINLE CENGAGE Learning.

[3] Davison, J. and Dowson, D. (2003). Learning to teach English in the secondary school: A companion to school Experience. London and New York: RoutledgeFalmer.

[4] Frodesen, J., \& Holten, C. (2003). Grammar in the ESL writing class. In B. Kroll (Ed.), Exploring the dynamics of second language writing (pp.141-161). Cambridge University Press.

[5] Halliday, M.A.K (1985). An introduction to functional grammar. London: Arnold.

[6] Krashen, S.D. (1982). Principles and practice in second language acquisition. Pergamon Press.

[7] Nunan, N. (2009). Second language teaching and learning. Cengage Learning.

[8] Nunan, D. (2003). Practical English language teaching (First Edition). New York: McGraw Hill.

[9] Richards, J., Platt, J., and Weber, H. (1985). Longman Dictionary of Applied Linguistics. London: Longman.

[10] Silva, T. (1993). Toward an understanding of the distinct nature of L2 writing: The ESL research and its implications. TESOL Quarterly, 27 (4), 657-677.

[11] Wharton, S. and Race, P. (2005). 500 tips for TESOL (Teaching English to speakers of other languages) RoutledgeFalmer, Taylor \& Francis Group

[12] Wharton, S. and Race, P. (2018). Why should I learn English?-10 compelling reasons for EFL Learners at https://www.oxfordroyale.co.uk>articles.

[13] Wharton, S. and Race, P. (2018). Why should I learn English?-10 compelling reasons for EFL Learners at https://www.oxfordroyale.co.uk>articles. 